\title{
RIH intermediate section casing in Bazian-1 exploration oil well
}

\author{
A. K. Darwesh \\ Petroleum Engineering Department, Engineering Faculty, \\ Koya University, Kurdistan
}

\begin{abstract}
Oil well drilling operation is the subject of many activities, and for each part of its works and activities there is a particular tender for time schedule, quality and cost. I want to go back over an event which began in 2009 and finished 15 months later after continuous operation; the Bazian exploration oil well, Bn-1. As far as I am concerned, the most important point that I want to convey is the relation between the three main points above, giving attention to these aspects and asking some questions in this regard, which will be easy for me to answer because I was working there and I was a part of those operations. New technology, a professional team, logistic support, security, skilled staff and team work were all main elements hidden within the above-mentioned main activities.

The aforementioned uses only a normal running of casing pipes, and these operations will normally take one day, but in the Bazian Bn-1 exploration oil well the time taken was more than one month. In this paper I want to make a very quick review of most of the operations performed for running 9-5/8" casing for the interval from $1195 \mathrm{~m}$ to $2028 \mathrm{~m}$, which will clearly show that after three attempts we were not able to run the casing $100 \%$ as planned, and I will provide a technical recommendation for future operations in a similar situation.

Keywords: oil and gas law, KRG, PSC contracts, exploration blocks.
\end{abstract}

\section{Introduction}

Since passing the oil and gas Law in Kurdistan, in August 2007, KRG has awarded more than 20 exploration blocks under PSCs to the oil operators. On November 2008, 30 exploration blocks have been fully awarded to foreign oil companies [1], one of these oil operators was Korean National Oil Corporation (KNOC) as an 
operator for Bazian Block, west of Sulaimaniyha, north of Iraq. The first exploration oil well was Bn-1 in Bazian Block under PSC contract. Normally drilling operation is the first and the most expensive step in the oil and gas industry for any block. Generally, expenditures for drilling processes represent about $25 \%$ of the total oilfield exploitation cost and are concentrated mostly in exploration and development of well drilling [2].

October 1st, 2009 was the start date of the Bn-1 oil well in Bazian block west of Sulaimaniyha Governorate near Aghjalar sub-district [3].

Here I want to go through the Bn-1 ST1 which was planned to run 9-5/8" casing, but it was too difficult to set $9-5 / 8$ " casing because of tight spots and wash out zones. Table 1 gives us a brief description of most of the operations before setting 9-5/8" casing. Of course the drilling operation in this section was exposed for a long time due to many technical and communication problems. In this study; here I want to present more information regarding only the $9-5 / 8$ " casing running operation and the main technical problems such as tight spot, pack off and bridge zones.

Table 1: Casing data for Bn-1 [4].

\begin{tabular}{|c|c|c|c|c|c|c|c|c|}
\hline OD (") & ID (") & MD (m) & TVD (m) & WT (lbs/ft) & Grade & $\begin{array}{c}\text { Burst } \\
(\mathrm{psi})\end{array}$ & $\begin{array}{c}\text { Collapse } \\
(\mathrm{psi})\end{array}$ & $\begin{array}{c}\text { Tensile } \\
(\mathrm{klbs})\end{array}$ \\
\hline $30 "$ & 27 & 17.5 & 17.5 & 453.15 & $\mathrm{X} 52$ & & & \\
\hline $20 ”$ & $18.73 ”$ & 467 & 467 & 133 & $\mathrm{~K}-55$ & 3,060 & 1,493 & 2,100 \\
\hline $133 / 8 "$ & $12.415 ”$ & 1196 & 1195 & 68 & $\mathrm{~L}-80$ & 5,020 & 2,260 & 1,556 \\
\hline $95 / 8 "$ & & & & & & & & \\
\hline
\end{tabular}

\section{Hole problems}

Tight spot it is a situation when the driller attempts to pull the casing string through these sections, and may experience resistance (Figure 1).

Bridge is the accidental plug off of pore spaces or fluid paths in a rock formation, or to make a restriction in a wellbore or annulus. Bridges may be partial or total, and is usually caused by solids (drilled solids, cuttings, caving or junk) becoming lodged together in a narrow spot or geometry change in the wellbore (Figure 1).

Pack off is when the drilling fluid is not properly transporting cuttings and caving in/or of the annulus, or portions of the wellbore wall collapse around the drill string. When the well packs off, there is a sudden reduction or loss of the ability to circulate, and high pump pressures follow. If prompt remedial action is not successful, an expensive episode of stuck pipe can be the result. 


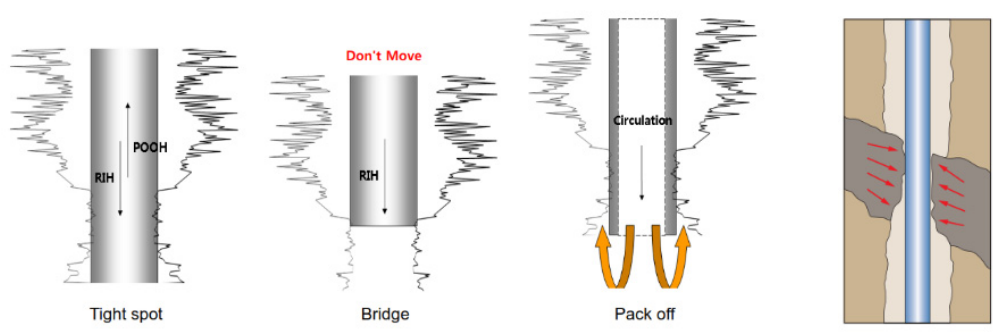

Figure 1: Problems in Bn-1.

\section{Event summaries}

\subsection{Drilling to TD (2028m)}

The drilling process with 12 1/4" started from $1196 \mathrm{~m}$ and after the drilling process with $121 / 4$ " bit was reached it is TD at $2028 \mathrm{~m}$, there was no ability to case the section directly due to presence of tight spots. Back reaming was performed to $1200 \mathrm{~m}$, followed by reaming down to $2028 \mathrm{~m}$ again. There were many tight spots until the last back reaming; reaming parameters was $25 \mathrm{rpm}, 650 \mathrm{gpm}$. When the back reaming process started, the mud pump flow rate GPM was decreased down to $500 \mathrm{gpm}$, and then POOH started, we can say that NPT was in increase with the depth, the number of tight spots also increased with the depth, see Figure 2 for tight spots and other parameters with the time.

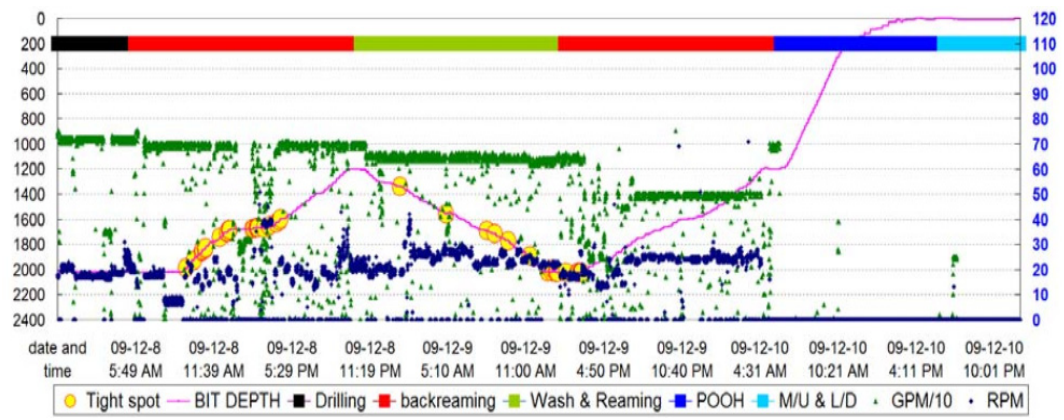

Figure 2: Tight spots and other parameters with the time.

\subsection{Casing running attempt \#1}

There was a plan for running the 9-5/8" casing pipes with ECP + DV tool for two stage of cement job. At $1268 \mathrm{~m}$ we felt the presence of the first tight spot, with the use of mud circulating the casing process went down through this tight spot. Then at $1330 \mathrm{~m}$ there were bridged and pack off. So there was a decision of using mud circulation again but this idea was not successful, finally the decision was changed to POOH using $35 \mathrm{gpm}$ of mud flow (see Figure 3 ). 


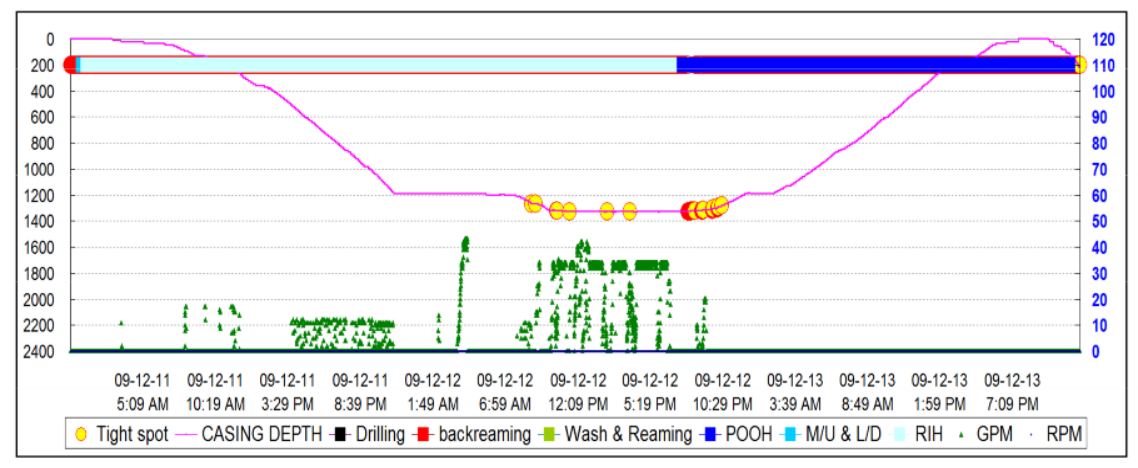

Figure 3: Casing running attempt \#1.

\subsection{Washing, reaming and back reaming \#1}

After the observation of many tight spots, the next step was $\mathrm{M} / \mathrm{U}$ a new BHA as in Table 2 and RIH to $2028 \mathrm{~m}$, RIH was with circulating and rotating, sometimes there was mud circulating only because the torque was zero.

Table 2: BHA of cleanout.

\begin{tabular}{|c|c|c|c|c|}
\hline BHA \# & Cleanout assembly & & & \\
\hline Item & Qty & OD (") & ID (") & Length \\
\hline Bit $121 / 4 " 3 \times 22 \mathrm{~s}$ & 1 & $121 / 4 ”$ & & 0.34 \\
\hline Bit sub/float & 1 & $8 ”$ & $2.7 / 8$ & 0.64 \\
\hline 8"Dcs & 6 & $81 / 16 ”$ & $27 / 8$ & 52.11 \\
\hline Jar & 1 & $81 / 8 ”$ & $31 / 2$ & 5.64 \\
\hline 8 "Dcs & 9 & $81 / 16 ”$ & $27 / 8$ & 79.12 \\
\hline XO & 1 & $81 / 16 ”$ & $27 / 8 ”$ & 1.10 \\
\hline 15 HWDP & 15 & $5 "$ & 3 & 139.90 \\
\hline
\end{tabular}

We can observe from the below PLOT Figure 4, the first washing and reaming time, reaming parameters were as about 90rpm and $720 \mathrm{gpm}$. Back reaming parameter was as $600 \mathrm{gpm}$ at same rpm. With the cyclic operation going on to more depth the tight spot zones were decreasing. After reaming and back reaming for three times there was a decision to $\mathrm{POOH}$ and starting another attempt for running the casing. 


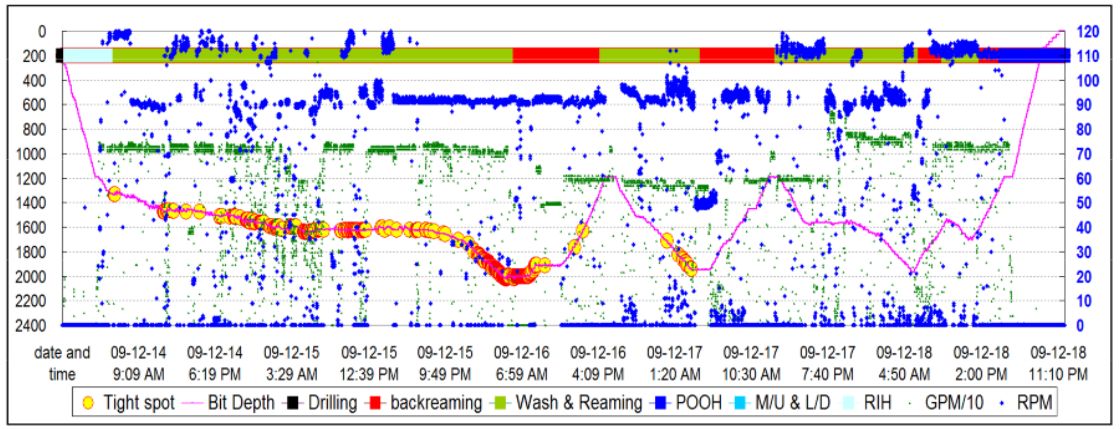

Figure 4: Washing, reaming and back reaming \#1.

\subsection{Casing running attempt \#2}

After M/U the casing shoe joint and starting to RIH, exactly at $1409 \mathrm{~m}$ the first tight spot was encountered, so the normal discussion was to start operating the mud pumps with this there was the ability to pass this and run the casing to $1532 \mathrm{~m}$. At $1532 \mathrm{~m}$ there was a bridge, all the attempts was to clear this bridge by lifting one joint was not a successes attempt, so another decision was taken to $\mathrm{POOH}$ the casing again, as it is clear in Figure 5 below.

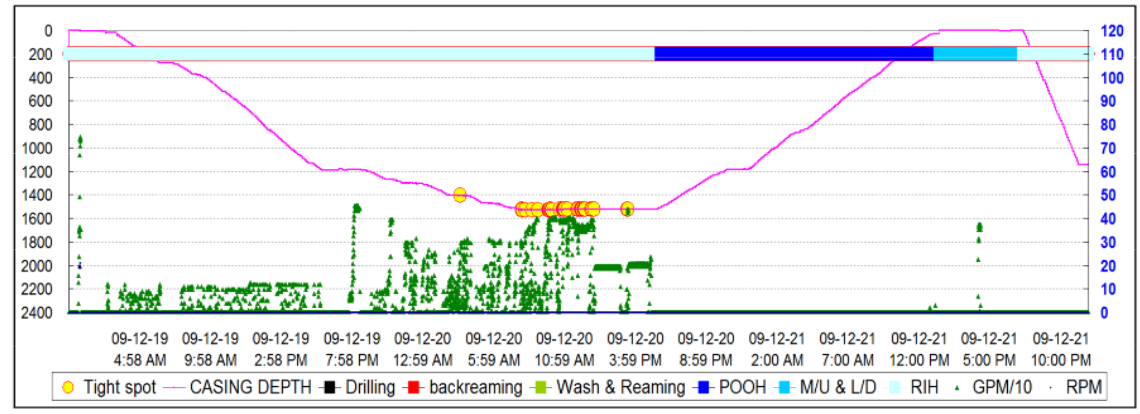

Figure 5: Casing running \#2.

\subsection{Cement plug}

To solve all these problems, the head quarter (HQ) decision was to set cement plug from $2028 \mathrm{~m}$ up to $1928 \mathrm{~m}, \mathrm{M} / \mathrm{U}$ the $81 / 2$ " BIT with open nozzle and 5" drill pipes only, still there were tight spots in our $121 / 4$ " hole section. The used flow was only $90 \mathrm{gpm}$ in the areas of tight spots. Starting going down with rotation, this RIH string was without any big problems. Pumping the slurry to set the plug from $2028 \mathrm{~m}$ up to $1928 \mathrm{~m}$, see Figure 6 below. 


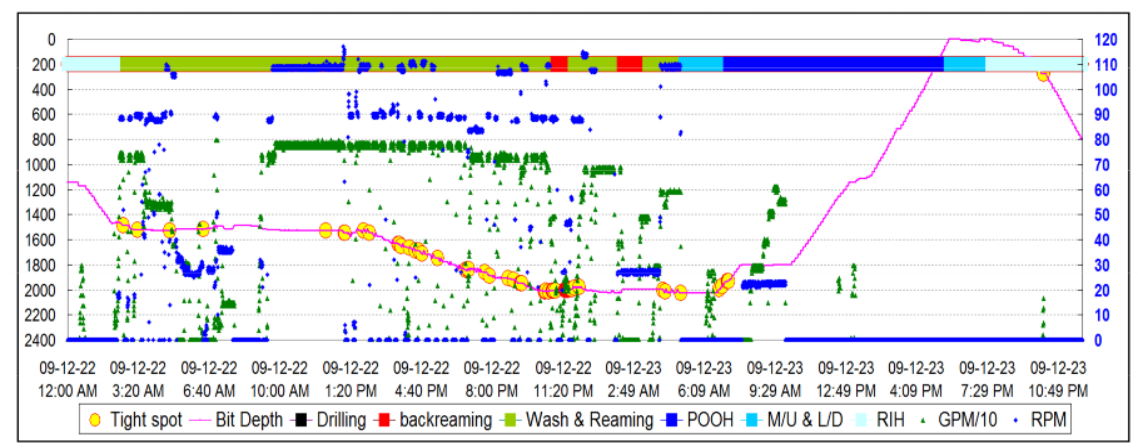

Figure 6: 8 1/2” BIT cement plug.

\subsection{Washing and reaming, back reaming \#2}

A new 12 1/4" BHA was M/U with Roller Reamer and RIH was performed. At $1518 \mathrm{~m}$, there was tight spot, with the use of the 730GPM, 100rpm, drilling was continued. Increasing mud weight up from $12.5 \mathrm{ppg}$ to $13.5 \mathrm{ppg}$ perfumed, reaming and back reaming several times, after that all tight spots were disappeared. Here I can say that the Roller reamer was worked properly, raising mud weight from $12.5 \mathrm{ppg}$ to $13.5 \mathrm{ppg}$ then to $15 \mathrm{ppg}$ was another reason in controlling the problems of tight spots. Start POOH the BHA Figure 7 is the description of that situation.

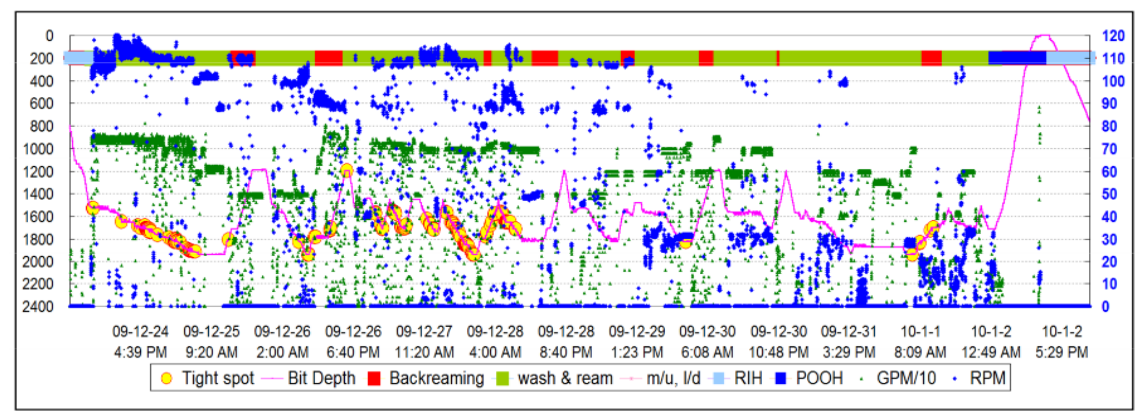

Figure 7: Washing and reaming, back reaming \#2.

\subsection{Casing running \#3}

M/U the normal casing $95 / 8$ " for one stage cement, LIPSTICK SHOE and WATER BUSHING went normally till $1568 \mathrm{~m}$ in which there was again the first tight spot encountered. With the use of mud circulating $300 \mathrm{gpm}$, rotation of 10 rpm and the use of water bushing, this problem was solved. In continuing in RIH, many other tight spots encountered, by using the same procedure there was an ability to overcome and reaching to depth of $1839 \mathrm{~m}$ very slowly. Here there was a bridge and no ability to go down any more, then the decision was to cement the casing at $1839 \mathrm{~m}$ (Figure 8). 


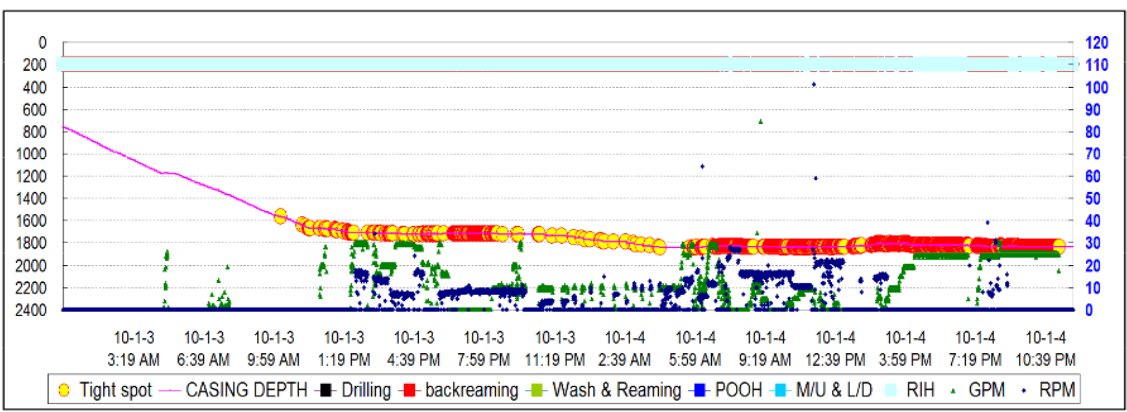

Figure 8: Casing running \#3.

\section{Result and conclusions}

\subsection{Wellbore instability}

The main reason behind all these exposed long time (from Dec 1st, 2009 to Jun 5, 2010 ) is the well was tectonically under stressed areas of fault zone. As we can observe from 8-1/2" pilot hole caliper log data (Figure 9), from 1196m to $1673 \mathrm{~m}$, there was more percentage of clay-stone interval zone as Aliji formation, from $1500 \mathrm{~m}$ to $1650 \mathrm{~m}$ there was wash out zone and from $1673 \mathrm{~m}$ to $1945 \mathrm{~m}$ there was muddy limestone and clay-stone as Tanjero formation.

Mud weight was also another important factor, in this well there was a lot of lost circulation, generally, during the LOC there will be a reduction in mud weight and pumping LCM will start. But unfortunately the decision was to use $12.0 \mathrm{ppg}$ Mud weight and then $14.5 \mathrm{ppg}$.
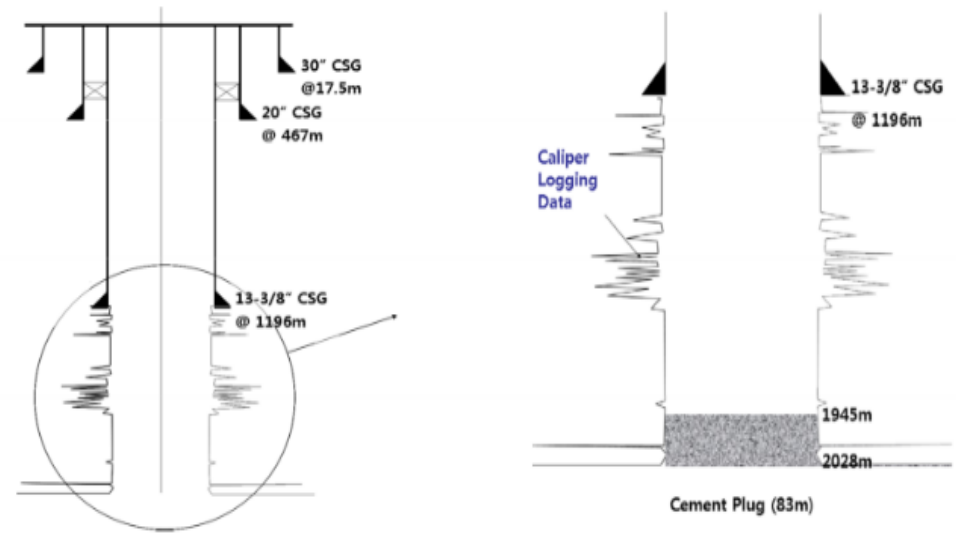

Figure 9: Well-bore instability. 


\subsection{Analyzing real time data}

In Figure 10 below we can observe that after the first casing running was failed, there was an operation of reaming and back-reaming. By making a comparison between each casing operation we can observe that the tight spots presence were depend on the operation situation.

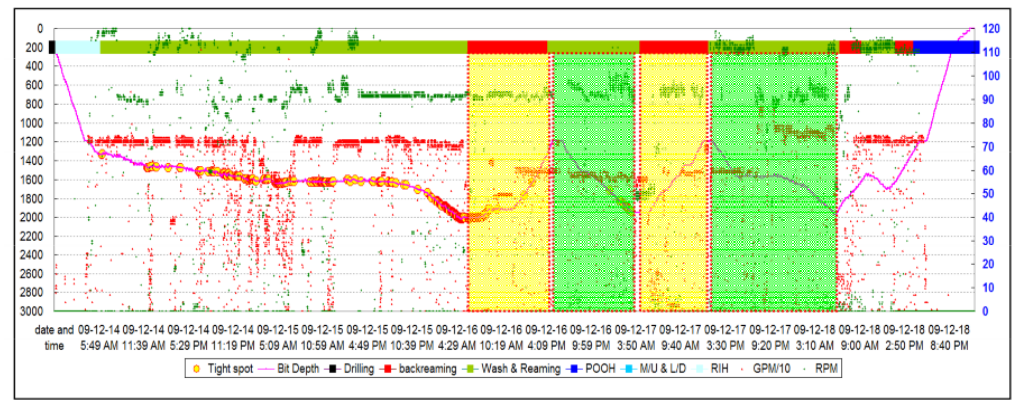

Figure 10: Real time data analysing.

If there was only circulation in the intervals of not tight spot (no rotation), WOH was decreased constantly, SPP was the same, (Figure 10 plot).

The black circle is tight spot on Dec, $162: 22 \mathrm{PM}$ to 4:52PM, SPP and WOH value was constant, rotating in free spot zone, and also the same. But during or in tight spot, WOH or SPP increased dramatically, (Figure 11) at 2:22pm SPP was the same, but Torque was dramatically increased.

If we look at the plot Figure 12, which represents the second back reaming, we can see that the back reaming parameter was 95rpm without circulating mostly. The use of circulation was only done when torque and SPP were in increase. In this section, we can observe a big washout zone so may be the cutting was not removed properly in washout zone. After 12-17 11:36 am, circulating was $600 \mathrm{gpm}$, rotation $95 \mathrm{rpm}$. Somehow the tight spot doesn't appear even if the torque picks two times.

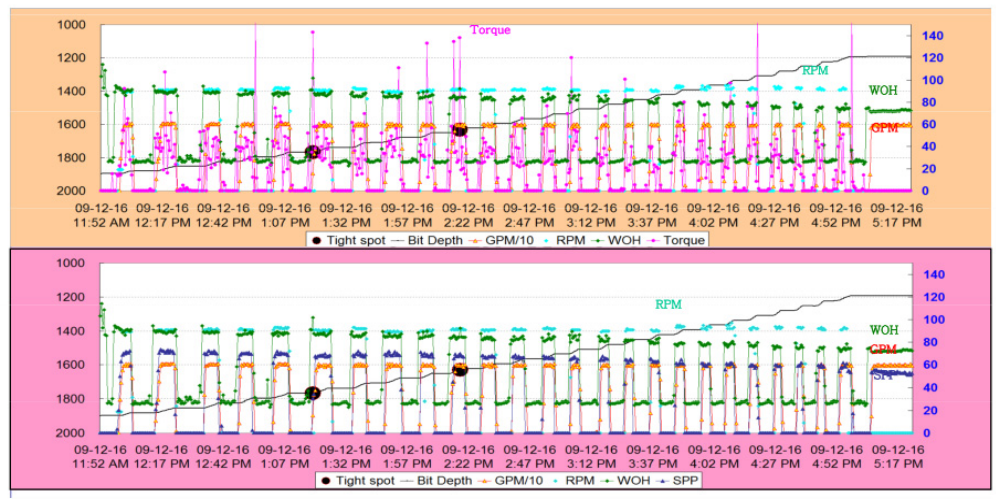

Figure 11: WOH increased. 


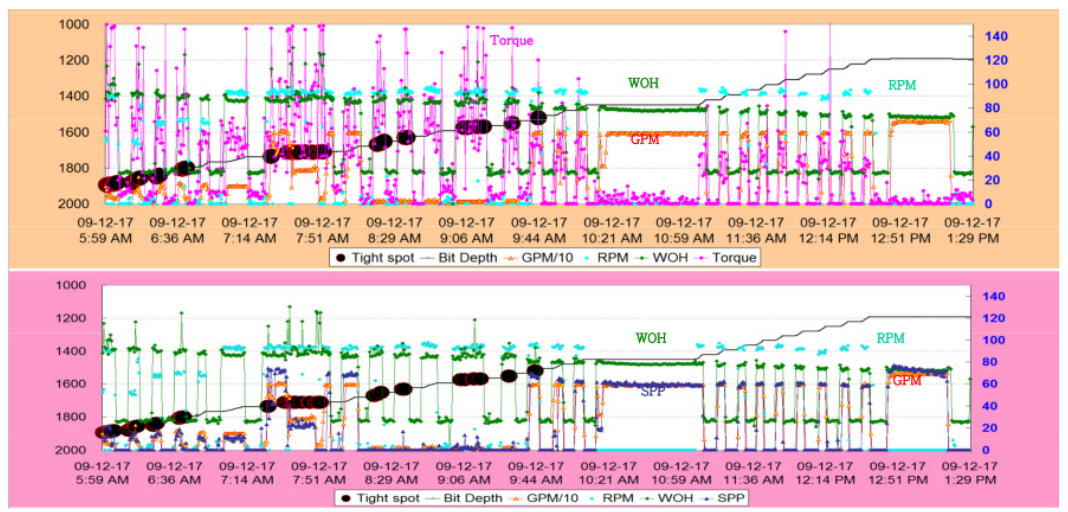

Figure 12: Second back reaming.

\subsection{Reaming parameter}

Back reaming operation is a more difficult operation in hole cleaning than normal reaming. But in this well (Bn-1) it was not, see the plot below (Figure 13), during the first reaming operation, the reaming parameter was 95rpm, 600gpm, and there was no tight spot. WOH was constantly increasing and torque was normal, see Figure 13 below.

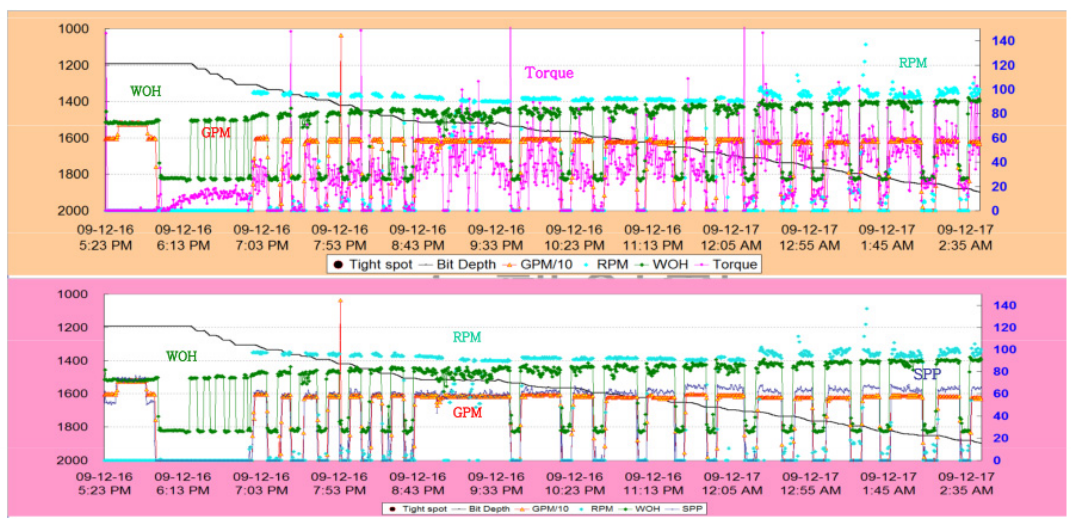

Figure 13: Reaming parameters.

In the second reaming operation the parameters were 95-110rpm, the flow was $600-750 \mathrm{gpm}$. The torque and SPP were increased dramatically. Checking the parameter rpm was increased more than before. There was no tight spot from $1200 \mathrm{~m}$ to $1500 \mathrm{~m}$ but after $17 \mathrm{Dec}, 5 \mathrm{pm}$ torque and SPP were increased and because of that we saw a decrease in rpm, and an increase of flow at 95rpm to $750 \mathrm{gpm}$ means that there was difficulty in cleaning the hole conditions. Although torque was about normal but SPP increased at 7:50 pm. This situation supports the probability of caving presence in the washout zone and cutting fallen between in gauge hole and drill string. 


\section{Results}

We can discuss the hole cleaning process through the following points:

1. From $1196 \mathrm{~m}$ to $1673 \mathrm{~m}$, there was washout zone, reaming and back reaming practice was easy to $\mathrm{POOH}$ than RIH. Sometimes the BHA was bridged in edge of formation of washout zone this of course supports the unstable tectonic intervals.

2. During the back reaming operation, sometimes it's necessary to circulate, but the presence of tight spots support that most times the circulation itself can leave more hole problems.

3. Although we have to monitor the shale shakers as we don't properly know the circulating rate per different zones, through checking the cutting in the shale shaker we can also control the circulating rate.

\section{Recommendations}

Casing running method in tight spot.

\subsection{Water bushing}

Using reamer shoe as in Figure 14 is normal, but if there was a probability to face more tight spots it will make the condition more difficult with a lot of problems, and so here we need another tool, which is water bushing. Water bushing gives casing the ability of rotation. So it's possible to run casing in tight spot and rotate them also. Water bushing is installed between the top drive and the casing coupling.

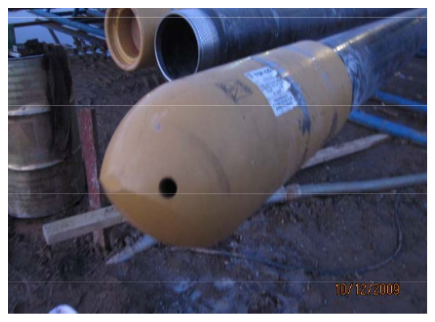

9-5/8" Lipstick shoe

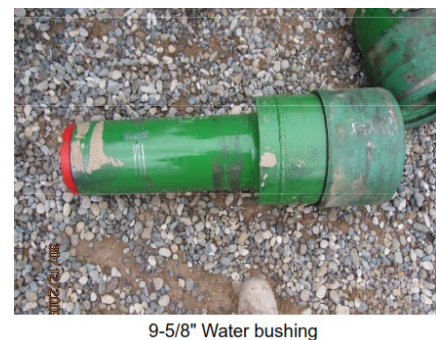

9-5/8" Water bushing

Figure 14: Tools with casing running.

\subsection{Casing drilling}

Casing reaming or casing drilling as a new technology have been introduced in this regard, which can be used, for the next run of casing in the next well in tight spot, consideration of this technology is important to solve and over on these problems. Casing drilling has been employed in many countries as an effective method of reducing the overall drilling costs by reducing drilling time and drill string problems encountered during conventional drilling process [5]. 
Drilling rigs used for casing drilling can be specially developed for this technology or modified conventional drilling rigs [6]. The Turbo-caser system allows reaming without casing rotation and, because it is fully drillable, it represents much reduced operational risk and increased confidence of success. It works with all casings and liners, with or without a top drive, and no additional crews are needed.

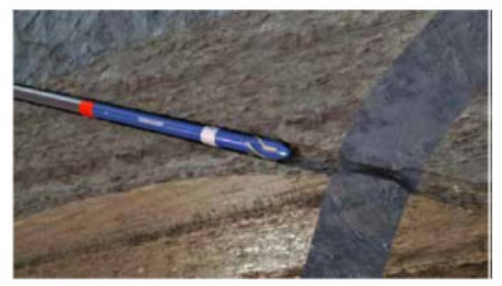

Run casing/liner with Turbocaser

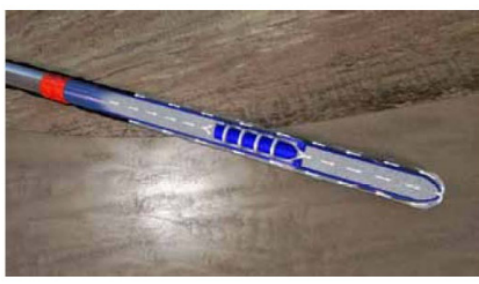

Cement casing and reamer in place

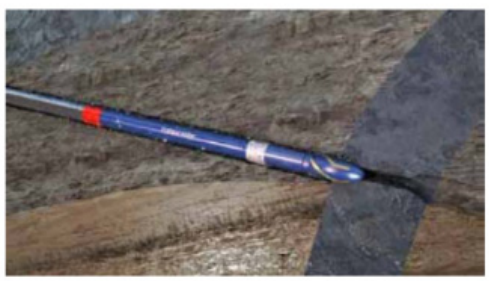

Reaming through obstructions

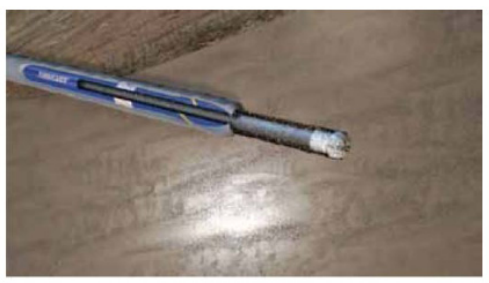

Drill-thru into new hole

Figure 15: Turbo caser.

\section{References}

[1] KRG, Consul of Ministers, Ministry of Natural Resource.

[2] Handbook of Best Practices for Geothermal Drilling, John Finger and Doug Blankenship, http://www1.eere.energy.gov/geothermal/pdfs/drillinghandbook.pdf.

[3] Daily reports, KNOC, Korean National Oil Corporation work in Bazian, Sulaimani office.

[4] Daily Reports, KNOC, Korean National Oil Corporation work, Rig site Daily Reports.

[5] Casing Drilling Technology, Nediljka Gaurina-Međimurec, University of Zagreb, Faculty of Mining, Geology and Petroleum Engineering, Pierottijeva 6, 10000 Zagreb, Croatia.

[6] Fontenot, K., Highnote, J., Warren, T., Houtchens, B., (2003): Casing Drilling Expands in South Texas, paper SPE/IADC 79862, presented at the SPE/IADC Drilling Conference, Amsterdam, The Netherlands, 19-21 February 2003.

[7] Casing Drilling Technology, Nediljka GAURINA-Međimurec, University of Zagreb, Faculty of Mining, Geology and Petroleum Engineering, Pierottijeva 6, 10000 Zagreb, Croatia. 